\title{
Hypersensitivity of lung vessels to catecholamines in systemic hypertension
}

\author{
MAURIZIO D GUAZZI, MARINA ALIMENTO, CESARE FIORENTINI, MAURO PEPI, \\ ALVISE POLESE
}

\begin{abstract}
Among patients with primary systemic hypertension pressure and arteriolar resistance in the pulmonary circulation exceed normal values and are hyper-reactive to sympathetic stimulation. A study was therefore carried out in 16 patients with uncomplicated essential hypertension and nine healthy subjects to compare the pulmonary vascular reactivity to exogenous catecholamines. In the normotensive group the dose response relation to adrenaline ( $\mu \mathrm{g}$ : dyn) was $1=-4,2=-9,3=-9$, and $4=-10$ and to noradrenaline $2=+3,4=+8,6=+4$, and $8=+3$. The relations in the hypertensive subjects were $1=+18,2=+42,3=+59$, and $4=+77$ and $2=+39,4=+54,6=+76$, and $8=+100$, respectively. Group differences were highly significant. Cardiac output (blood flow through the lungs) was raised by adrenaline and reduced by noradrenaline. In either case the driving pressure across the lungs was significantly augmented in the hypertensive patients but not in the normotensive group.

Both catecholamines had a vasoconstrictor effect on the pulmonary circulation as a result of vascular over-reactivity. The opposite changes in resistance between normal and hypertensive subjects produced by adrenaline suggest that a constrictor vascular hypersensitivity occurs in the pulmonary circulation with the development of systemic high blood pressure.
\end{abstract}

Istituto di Cardiologia, Centro di Studio per le Ricerche Cardiovascolari del Consiglio Nazionale delle Ricerche, Istituto "G Sisini," University of Milan, Italy

MAURIZIO D GUAZZI, MD, PHD, chairman of cardiology

MARINA ALIMENTO, $\mathrm{MD}$, research fellow

CESARE FIORENTINI, MD, associate professor of cardiology

MAURO PEPI, MD, research fellow

ALVISE POLESE, MD, associate professor of cardiology

Correspondence to: Dr Maurizio D Guazzi, Istituto di Cardiologia, Via Bonfadini 214, 20138 Milano, Italy.
Introduction

Pulmonary arterial pressure ${ }^{1}$ and arteriolar resistance ${ }^{2}$ among patients with systemic hypertension significantly exceed values in normal controls. These changes are not explained ${ }^{2}$ by the mechanical or chemical factors known to be concerned in the regulation of pulmonary vasomotility in man. ${ }^{3}$ Lung vessels in essential hypertension are also over-reactive to adrenergic activation during mental arithmetic and the cold pressor test. ${ }^{+}$This may either be due to alterations of vascular receptors or excitation-contraction coupling (smooth muscle sensitivity) or wall thickening and narrowing of the lumen, or reflect abnormal levels of external activation.

We have evaluated the responsiveness to exogenous catecholamines in an effort to settle these questions.

\section{Subjects and methods}

Sixteen hypertensive men with a mean age of 45 (SD 3.8) years and mean weight of 73 (6) $\mathrm{kg}$ were admitted to hospital and given infusions of adrenaline and noradrenaline. All had supine diastolic pressures of between 95 and $110 \mathrm{~mm} \mathrm{Hg}$ on repeated measurement and none had ever received antihypertensive agents. No patient had an urgent need for treatment; evidence of cardiac, lung, or cerebrovascular disease; or an underlying renal or endocrine cause of the hypertension. Respiratory gas values and $\mathrm{pH}$ of the arterial blood were normal. Controls were nine normotensive men (mean age 47 (SD 4.6) years; mean weight $71(5 \cdot 2) \mathrm{kg}$ ) who had been admitted to hospital for atypical chest pain and in whom coronary disease was excluded by angiography. They had normal arterial oxygen and carbon dioxide tensions and $\mathrm{pH}$ values and were not receiving any form of treatment.

For the right sided pressure and cardiac output measurements a triple lumen $7 \mathrm{~F}$ thermodilution balloon tipped catheter (Edwards Laboratories) was inserted percutaneously into an antecubital vein and advanced to the pulmonary artery or, when necessary to the wedge position. Systemic arterial pressure was measured in the right brachial artery through a Teflon catheter needle. These procedures were carried out under local anaesthesia. Pressures were determined with Statham strain gauge transducers with zero reference level $5 \mathrm{~cm}$ below the sternal angle. Cardiac output was determined by the thermodilution method. Systemic vascular resistance (SVR) and pulmonary arteriolar resistance (PAR) were calculated as follows: $\mathrm{SVR}=$

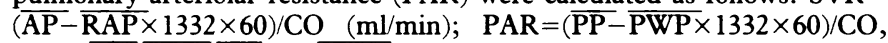
where $\overline{\mathrm{AP}}, \overline{\mathrm{RAP}}, \overline{\mathrm{PP}}$, and $\overline{\mathrm{PWP}}$ are mean systemic, right atrial, pulmonary 
arterial, and pulmonary wedge pressures and $\mathrm{CO}$ is cardiac output. The circulatory variables and pleural pressure, estimated by the method of MilicEmili et al, 5 were recorded on a Gould-Brush eight-channel recorder, model 480. Arterial oxygen and carbon dioxide tensions and $\mathrm{pH}$ were measured as described. ${ }^{2}$

Study sessions were carried out in the morning one week after admission. Patients were first familiarised with the investigators and had been instructed not to smoke or take alcohol or foods containing caffeine for 24 hours. After lying supine for at least 30 minutes the subjects received infusions of adrenaline $(8 \mathrm{\mu g} / \mathrm{ml}$ in $5 \%$ dextrose in water) and noradrenaline $(16 \mu \mathrm{g} / \mathrm{ml}$ in $5 \%$ dextrose in water) at initial doses of 0.5 and $1.0 \mu \mathrm{g} / \mathrm{min}$ for three minutes, respectively. Infusions were given through the proximal port of the venous catheter placed at the level of the right atrium and regulated by a constant infusion pump. Doses of adrenaline and noradrenaline were increased to $1,2,3$, and 4 and $2,4,6$, and $8 \mu \mathrm{g} / \mathrm{min}$, respectively, with a washout period of at least 15 minutes between each infusion. Drugs were infused in random order. Continuous records of heart rate and pleural, aortic, and pulmonary pressures were obtained throughout. Cardiac output, pulmonary wedge pressure, and arterial oxygen and carbon dioxide tensions and $\mathrm{pH}$ were measured and systemic and pulmonary arteriolar resistance calculated as baseline values and during the largest pressure variations at each step of the catecholamine infusions.

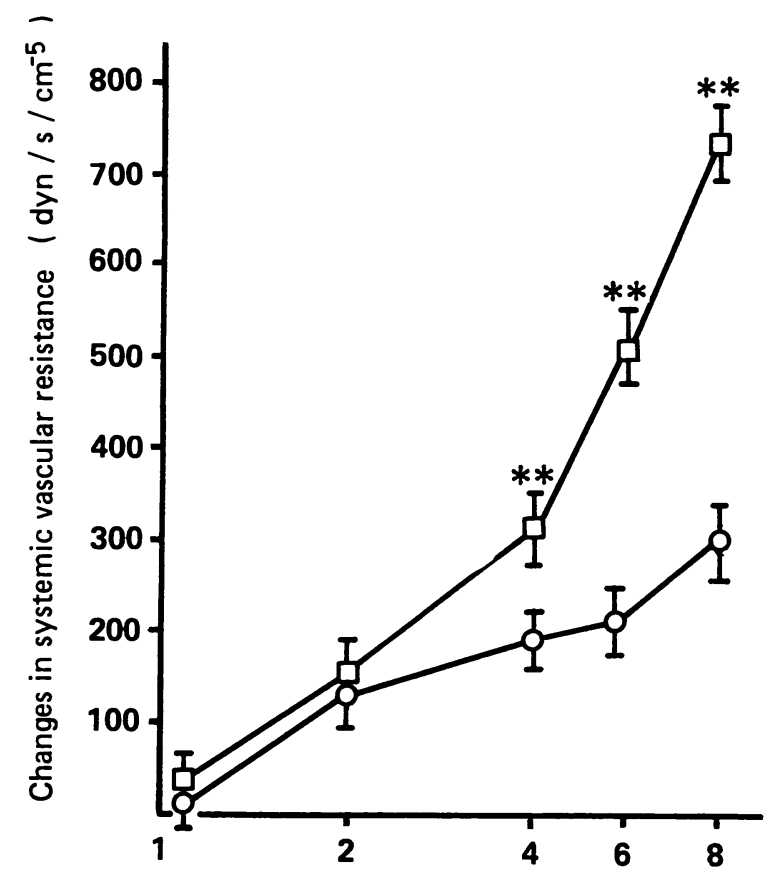

Results were expressed as means and SD; significance of differences from the baseline values and between the two groups at each phase of the pharmacological tests was assessed by either one way or two way analysis of variance, as appropriate.

\section{Results}

The two groups of patients were well matched for age and somatic characteristics. Baseline pleural pressure, arterial oxygen and carbon dioxide tensions, and $\mathrm{pH}$ were similar to normal in the hypertensive population and in neither group did they change significantly during the catecholamine infusions.

The table shows the responses of pulmonary arterial pressure, mean pulmonary wedge pressure, pulmonary arteriolar resistance, and cardiac output to increasing doses of the two catecholamines compared with baseline values. Although cardiac output was increased by adrenaline and reduced by noradrenaline, the driving pressure through the lungs (difference between mean arterial and mean pulmonary wedge pressures) was augmented by either stimulus in the hypertensive patients and almost unchanged in the normotensive ones. In these latter subjects pulmonary arteriolar resistance

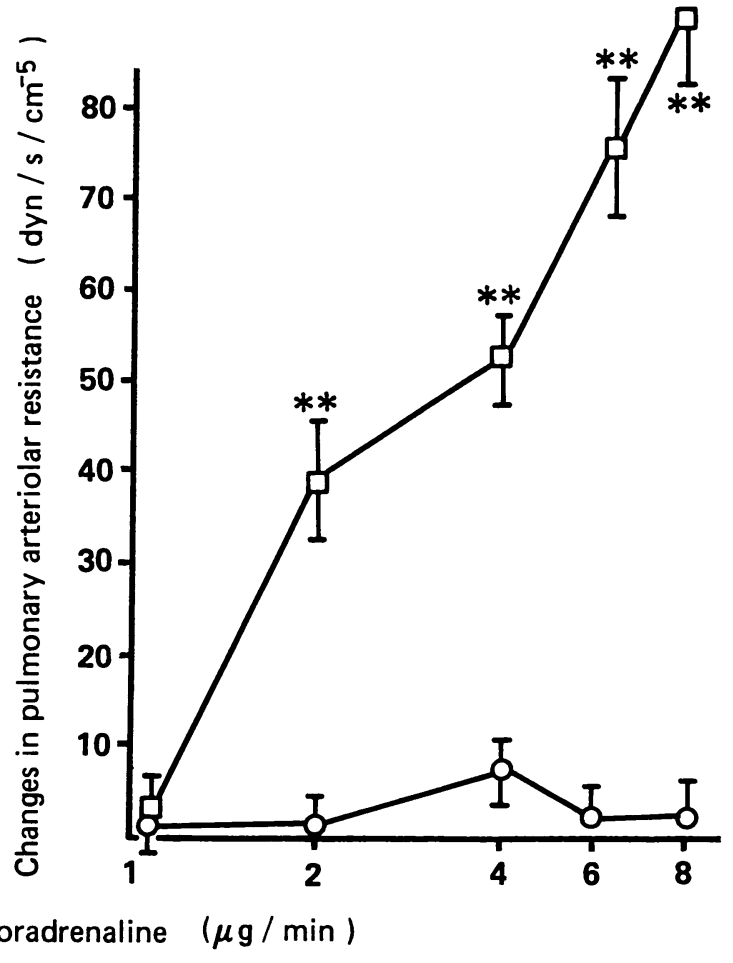

FIG 1-Mean sysstemic and pulmonary vasomotor responses evoked by noradrenaline in normotensive $(\bigcirc)$ and hypertensive $(\square)$ populations. Bars are SD.

$\star \star$ Difference from normotensive population significant at $p<0 \cdot 01$

Circulatory responses to increasing doses of noradrenaline and adrenaline in normotensive and hypertensive subjects. Values are means (SD in parentheses)

\begin{tabular}{|c|c|c|c|c|c|c|c|c|c|c|c|c|c|c|}
\hline & & \multicolumn{7}{|c|}{ Noradrenaline $(\mu \mathrm{g} / \mathrm{min})$} & \multicolumn{6}{|c|}{ Adrenaline $(\mu \mathrm{g} / \mathrm{min})$} \\
\hline & & Baseline & 1 & 2 & 4 & 6 & & 8 & Baseline & 0.5 & 1 & 2 & 3 & 4 \\
\hline \multicolumn{15}{|c|}{$\begin{array}{l}\text { Pulmonary arterial pressure } \\
(\mathrm{mm} \mathrm{Hg}) \text { : }\end{array}$} \\
\hline \multirow{2}{*}{ Systolic } & Normotensive & $18(5 \cdot 3)$ & $18(5 \cdot 3)$ & $19(4 \cdot 1)$ & $19(3 \cdot 8)$ & $20(6 \cdot 1)$ & 20 & $(5 \cdot 8)$ & $19(4 \cdot 9)$ & $19(4 \cdot 9)$ & $20(4 \cdot 4)$ & $20 \quad(4 \cdot 2)$ & $23 \quad(3.9)$ & $23 \quad(4 \cdot 6)$ \\
\hline & Hypertensive & $24(3 \cdot 2)$ & $24(3 \cdot 2)$ & $27(3 \cdot 3)$ & $28(2 \cdot 2)$ & $30 \star(3 \cdot 0)$ & $32^{\star \star}$ & * $(2 \cdot 7)$ & $23(3 \cdot 5)$ & $23(3 \cdot 5)$ & $24(3 \cdot 6)$ & $(2 \cdot 9)$ & $31^{\star \star}(3 \cdot 7)$ & $33^{\star \star \star}(3 \cdot 2)$ \\
\hline \multirow{2}{*}{ Diastolic } & Normotensive & $5(2 \cdot 4)$ & $5(2 \cdot 4)$ & $5(2 \cdot 3)$ & $5(2 \cdot 1)$ & $5(2 \cdot 3)$ & 5 & $(2 \cdot 2)$ & $5(2 \cdot 0)$ & $5(2 \cdot 0)$ & $4(2 \cdot 5)$ & $5 \quad(2 \cdot 6)$ & $5 \quad(2 \cdot 1)$ & $5 \quad(1.9)$ \\
\hline & Hypertensive & $8(2 \cdot 3)$ & $8(2 \cdot 3)$ & $11(2 \cdot 0)$ & $12(2 \cdot 1)$ & $15 *(2 \cdot 1)$ & $17^{\star \star \star}$ & $(2 \cdot 2)$ & $8(2 \cdot 3)$ & $8(2 \cdot 3)$ & $10(2 \cdot 2)$ & $14 * \star(2 \cdot 4)$ & $15 \star \star(2 \cdot 5)$ & $18 \star \star(2 \cdot 5)$ \\
\hline \multicolumn{15}{|c|}{$\begin{array}{l}\text { Mean pulmonary wedge pressure } \\
(\mathrm{mm} \mathrm{Hg}) \text { : }\end{array}$} \\
\hline Normotens & & $5 \cdot 3(1 \cdot 8)$ & $5 \cdot 3(1 \cdot 8)$ & $5 \cdot 6(2 \cdot 0)$ & $5 \cdot 3(1 \cdot 7)$ & $6.1(1.9)$ & $6 \cdot 5$ & $(1 \cdot 6)$ & $5 \cdot 2(1 \cdot 5)$ & $5 \cdot 2(1 \cdot 5)$ & $5 \cdot 0(1 \cdot 2)$ & $(1 \cdot 4)$ & $(2 \cdot 1)$ & $(2 \cdot 3)$ \\
\hline Hypertensi & & $5 \cdot 0(2 \cdot 0)$ & $5 \cdot 0(2 \cdot 0)$ & $5 \cdot 6(1 \cdot 6)$ & $6 \cdot 0(1 \cdot 8)$ & $7 \cdot 9(1.6)$ & $8 \cdot 7$ & $(2 \cdot 3)$ & $5 \cdot 0(1 \cdot 3)$ & $5 \cdot 0(1 \cdot 3)$ & $4 \cdot 8(1 \cdot 4)$ & $(1 \cdot 5)$ & $(1.8)$ & $(\mathrm{I} \cdot 8)$ \\
\hline \multicolumn{15}{|c|}{ Cardiac output $(\mathrm{ml} / \mathrm{min})$ : } \\
\hline Normotens & & $6125(220)$ & $6125(220)$ & $5776(200)$ & $5700^{\star}(195)$ & $5550^{\star \star}(205)$ & $5050 \star \star$ & $*(235)$ & $6050(201)$ & $6050(201)$ & $6280(227)$ & $6650^{\star \star \star}(291)$ & $7020^{\star \star}(285)$ & $7350^{\star \star}(264)$ \\
\hline Hypertensi & & $6340(265)$ & $6340(265)$ & $6070(215)$ & $5790 \star(181)$ & $5420 \star \star(282)$ & $5030^{\star \star \star}$ & $*(265)$ & $6150(195)$ & $6150(195)$ & $6515(203)$ & $6970 \star \star(277)$ & $7365 \star \star(299)$ & $7680^{\star \star}(280)$ \\
\hline \multicolumn{15}{|c|}{$\begin{array}{l}\text { Pulmonary arteriolar resistance } \\
\left(\text { dyn } / \mathrm{s} / \mathrm{cm}^{-5}\right) \text { : }\end{array}$} \\
\hline \multirow{2}{*}{\multicolumn{2}{|c|}{$\begin{array}{l}\text { Normotensive } \\
\text { Hypertensive }\end{array}$}} & $52(14)$ & $52(14)$ & $55 \quad(17)$ & 60 & 56 & 55 & (14) & $59(12)$ & $59(12)$ & $55 \quad(16)$ & $50 \quad(15)$ & $50 \quad(17)$ & $49 \quad(15)$ \\
\hline & & $102(13)$ & $102(13)$ & $141^{\star \star}(12)$ & $156^{\star \star *}(11)$ & $178 \star \star(16)$ & $202^{\star \star}$ & * $(18)$ & $104(11)$ & $104(11)$ & $122 * *(8)$ & $147 \star \star(19)$ & $163 \star \star(25)$ & $182^{\star \star *}(28)$ \\
\hline
\end{tabular}

*Difference from baseline significant at $p<0.05 . \quad$ * Difference from baseline significant at $p<0.01$ 

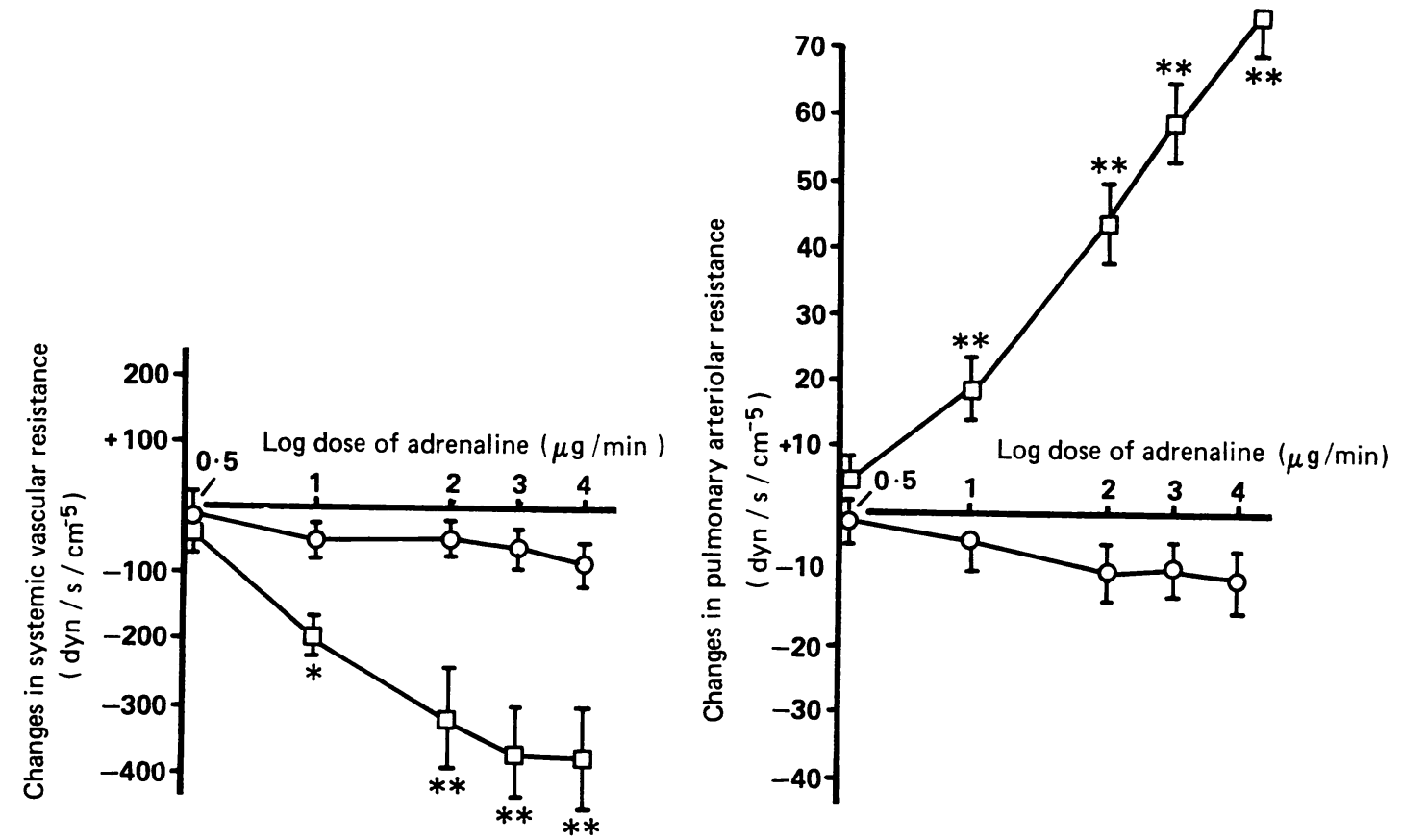

FIG 2-Mean systemic and pulmonary vasomotor responses to adrenaline in normotensive $(\bigcirc)$ and hypertensive $(\square)$ groups. Bars are SD.

${ }^{\star}$ Difference from normotensive population significant at $\mathrm{p}<0.05$.

$\star \star$ Difference from normotensive population significant at $\mathrm{p}<0.01$.

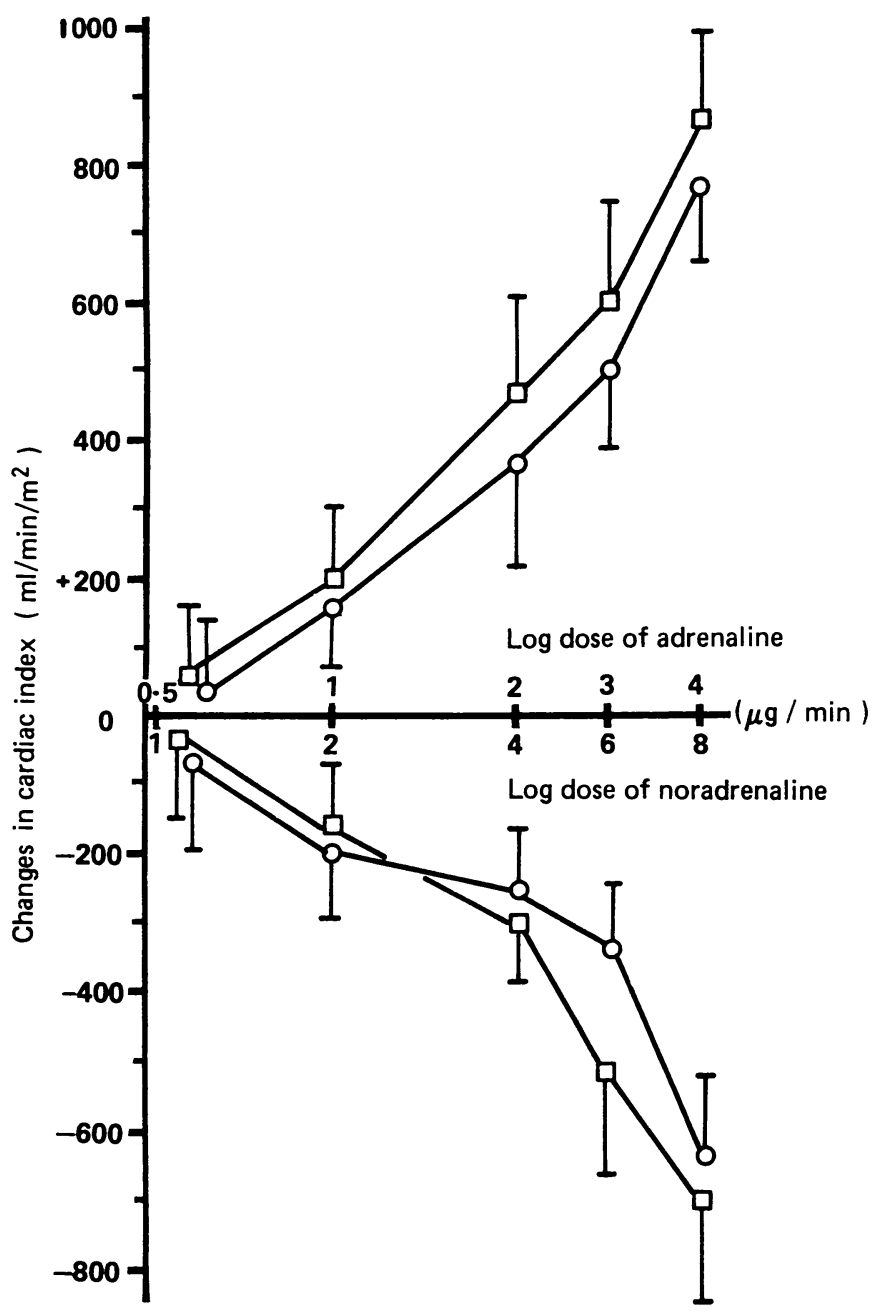

FIG 3-Mean responses of cardiac index to increasing doses of adrenaline and noradrenaline in normotensive $(O)$ and hypertensive $(\square)$ subjects. Bars are SD. did not vary during the noradrenaline test and fell during the infusion of adrenaline; changes, however, did not reach statistical significance. By contrast, in the hypertensive population, both catecholamines raised the resistance of the pulmonary circulation and differences from the baseline value were statistically significant at each infusion dose beyond the threshold.

Figure 1 plots the rise of systemic vascular and pulmonary arteriolar resistance with increasing doses of noradrenaline in the two patient groups. Configurations of the curves were similar for the two variables, but in the hypertensive group curves were steeper and evidently shifted to the left. Average variations from baseline of systemic resistance in the hypertensive population were significantly $(\mathbf{p}<0.01)$ different from those in the normotensive group at dosages of 4,6 , and $8 \mu \mathrm{g} / \mathrm{min}$, and pulmonary resistance exceeded normal values $(\mathbf{p}<0 \cdot 01)$ at all infusion rates beyond the threshold.

Figure 2 plots the changes in the same variables with increasing doses of adrenaline. Adrenaline had a depressor effect on systemic vascular resistance, which was more pronounced in the hypertensive subjects (differences between the two populations significant at $p<0.01$ at dosages of 2,3 , and $4 \mu \mathrm{g} / \mathrm{min}$ ). As described above, adrenaline induced opposite responses in the pulmonary bed in the two groups, arteriolar resistance being mildly depressed in the normotensive subjects and substantially enhanced in the hypertensive group; differences in changes were significant $(p<0.01)$ at all steps beyond the threshold.

Figure 3 shows the absolute variations in cardiac index evoked by adrenaline and noradrenaline infusions in the normotensive and hypertensive populations. At no infusion rate was the group difference statistically significant.

\section{Discussion}

A question that must be clarified is whether changes in pulmonary arteriolar resistance during catecholamine infusion in hypertensive subjects reflect active vasomotion.

Among the factors controlling flow through the lungs, those of mechanical origin are predominant and knowledge of the passive relation between pressure and flow is essential for interpreting physiological or pharmacological activities that also affect the heart and systemic circulation. If this relation is not linear changes in resistance when flow is also changing may not necessarily reflect active vasomotion. Studies in dogs suggest that this relation is linear ${ }^{6}$ and the same seems true of normal man in the supine 
position when flow is suddenly doubled; the actual passive pressure-flow relation with small changes in flow in man, however, is not known. In this study the increase in pulmonary blood flow promoted by adrenaline was associated with no change or a small reduction in the difference between the pulmonary arterial and wedge pressures in the normotensive population. Concomitantly there was a tendency for the pulmonary arteriolar resistance to fall. This effect may have resulted from passive adaptation to increased flow or from active pharmacological vasodilatation. By contrast, a similar increase in the cardiac index by the same stimulus in the hypertensive group promoted a substantial rise of the driving pressure across the lungs; it follows that changes in pulmonary arteriolar resistance under the influence of adrenaline reflected active vasoconstriction in these subjects. Of particular importance was the response to noradrenaline: though the cardiac index was reduced by a similar extent in the two populations, in the hypertensive group the driving pressure through the lungs became as great as during the infusion of adrenaline, suggesting that even greater vasoconstriction had occurred. Respiratory factors should be considered extraneous to these phenomena, since the measured variables (pleural pressure, arterial blood gas values, and $\mathrm{pH}$ ) were comparable at the baseline and during catecholamine infusions.

These pharmacological tests show that the systemic circulation is over-reactive to adrenaline (vasodilatation) and to noradrenaline (vasoconstriction) in hypertension but do not show whether the vascular over-reactivity derives from a specific abnormality in vascular sensitivity. Conclusions may be different when discussion is addressed to the pulmonary circulation. Noradrenaline had no appreciable effect on the pulmonary vascular tone in normotensive subjects and, in agreement with findings in cats ${ }^{8}$ adrenaline showed a slight vasodilative action in this group. Comparison of these data with those in other reports is difficult, because in several studies changes in left atrial pressure were ignored and most were carried out in patients with valve, myocardial, or pulmonary diseases. In contrast with these results, in hypertension both catecholamines had a vasoconstrictor effect. The dose response plot showing the rise of resistance with increasing doses of noradrenaline documents the existence of vascular over-reactivity. Though some evidence has been reported that spontaneously hypertensive rats are liable to have an increase in pulmonary arterial medial thickness, ${ }^{9}$ there is no information in man concerning the possibility of duplication in the pulmonary circulation of the structural vascular changes that occur in the systemic circulation in hypertension. ${ }^{10}$ The question, therefore, concerning the relation between constrictor over-reactivity and structure of the pulmonary vessels remains open. By contrast, the opposite direction of the changes in arteriolar resistance between normotensive and hypertensive subjects during an infusion of adrenaline leaves little doubt that a vasoconstrictor vascular oversensitivity becomes active with the development of hypertension. This does not favour increased wall thickness and narrowing of the lumen, since in this case a more pronounced fall rather than a rise in resistance would be expected.

Whether the oversensitivity depends on the fact that hypertensive subjects have a different quality ${ }^{11}$ or mixture of pulmonary receptors from normotensive people or different biochemistry in the excitation-contraction coupling ${ }^{12}$ or other vascular regulatory components $\mathrm{s}^{12}$ is a subject of investigation.

\section{References}

1 Ferlinz J. Right ventricular function in adult cardiovascular disease. Prog Cardiovasc Dis 1982;25:225-67.

2 Olivari MT, Fiorentini C, Polese A, Guazzi MD. Pulmonarv hemodynamics and right ventricular function in hypertension. Circulation 1978;57:1185-90.

3 Fishman AP. Dynamics of the pulmonary circulation. In: Dow P, ed. Handbook of phrsiologr. Sect 2. Circulation. Vol 2. Washington: American Physiological Society, 1963: 1667-743.

4 Fiorentini C. Barbier P, Galli C, et al. Pulmonary vascular overreactivity in systemic hypertension. A pathophysiological link between the greater and the lesser circulation. Hypertension 1985;7:995-1002.

5 Milic-Emili J, Mead J, Turner JM, Glauser EM. Improved technique for estimating pleural pressure from esophageal balloons. F Appl Physiol 1964;19:207-11.

6 Shouka AA, Bunner MJ. Frankl AE, Grene AS, Kall :207 CH. Car con control and the role of autoregulation in the systemic and pulmonary arterial pressure-flow

Harris P, Heath D. The human pulmonary circulation. New York: Churchill Livingstone, 1977: $128-30,182-8$

8 Hyman AL, Nandiwada P, Knight D, Kadowitz PJ. Pulmonary vasodilator responses to catecholamines and sympathetic nerve stimulation in the cat. Evidence that vascular $\beta-2$ adrenoceptors are innervated. Circ Res 1981;48:407-15.

9 Mc.Murtry IF, Petrun MD, Tucker A, Reeves JT. Pulmonary vascular reactivity in the spontaneously hypertensive rat. Blood Vessels 1979;16:61-70.

10 Schwartz SM. Smooth muscle proliferation in hypertension. State-of-the-art lecture. Hypertension 1984;6 suppl 1):56-61.

11 Ohsuzu F, Strauss HW', Homer CJ. The lung beta-receptor in the spontaneous hypertensive rat. fpn $\operatorname{Circ} \mathcal{F}$ 1984;48: 1203-9.

12 Guazzi MD, Polese A, Bartorelli A, Loaldi A, Fiorentini C. Evidence of a shared mechanism of vasoconstriction in pulmonary and systemic circulation in hypertension: a possible role of intracellular calcium. Circulation 1982;66:881-6.

13 Ellsworth ML, Gregory TJ, Newell JC. Pulmonary prostacyclin production with increased flow and sympathetic stimulation. $\mathcal{F}$ Appl Physiol 1983;55:1225-31.

Accepted 16.11 ay 1986

\section{YEARS AGO}

It must be very annoying to Signor Succi, who would fain be considered the "champion faster," to find a fellow countryman, a certain Stefano Merlatti, ready to forestall his proposed demonstration in Paris. Merlatti, indeed, would out-do Succi, for he proposes to fast for fifty days and nights, and not to make use of any mysterious red liquid, but to content himself with filtered water. It is difficult to speak seriously about these so-called experiments, which are of about the same scientific importance as the search for a mode of perpetual motion; but one circumstance in connection with Succi's fast may be pointed to as affording the only available means of testing his assertion that he took no food. During the month in which it is alleged that he took no food, he only lost a little over two stone in weight, yet his temperature was maintained at the normal point, and the movements of respiration and of the heart were unaffected. It does not need a very profound acquaintance with chemistry and physics to know that the maintenance of these functions of the body necessitates the consumption of a large quantity of force-producing material. It has been estimated by Professor Foster that the work done every day by the heart alone is about the amount performed by a man in the ascent of Snowdon. But Succi fenced, rode, swam, took long walks, and otherwise conducted himself like an athlete in training, so that he had not only to maintain his internal vital processes, but to supply the additional force required for all these external exercises; yet he only lost 441 grammes, or rather less than one pound avoirdupois, a day. This is the only well established fact about the so-called fast; and, upon the face of it, casts the gravest suspicion upon the whole story. This fact may be looked at from another point of view. The well-known experiments of Bidder and Schmidt have shown that a fasting animal loses as much as $/ 37$ of its body-weight a day; and yet it would appear that Signor Succi lost less than two pounds a day, which is only equal to a daily loss of $1 / 138$ of his body-weight. If one of these fasters were rigorously watched, carefully weighed from day to day, and the amount of force expended scientifically measured, facts of some value with regard to the wasting of the human body in inanition, analogous to those obtained by Chossat, Voit, and Bidder and Schmidt, with regard to certain animals, would be presented to physiology. But when asked to believe that force can be created out of nothing by "will power," and that the fundamental laws of physics and physiology are suspended in favour of a young gentleman who has already passed some time in a lunatic asylum, men of science may be excused if they decline to waste their time in serving on committees of inspection, or in discussing such wild propositions. (British Medical Fournal 1886;ii:829.)

Hence, temperance has made great progress, and has more to make, but rather in the direction of solids than of liquids. Many persons, who, drinking no alcohol, cannot drink less, still eat too much. They and their supporters, who do not always follow their example, should remember that temperance, amongst other things, demands, not that a glass of good ale or wine should be called poison, but that its votaries should not gorge themselves with animal food or bulky vegetables like potatoes. (British Medical Fournal 1886;i:1221.) 